\title{
Divided We Fall: Rethinking Biodiversity Planning in the Context of Development in Sub-Saharan Africa $\mathbb{C}$
}

\author{
Robert Kasisi ${ }^{1}$ \\ ${ }^{1}$ Faculty of Environmental Design, University of Montreal, Montréal, Canada \\ Correspondence: Robert Kasisi, Faculty of Environmental Design, University of Montreal, C.P. 6128, succursale \\ Centre-ville, Montréal Qc H3C 3J7, Canada. Tel: 514-343-6111 ext. 3409. E-mail: robert.kasisi@umontreal.ca
}

Received: July 24, 2012 Accepted: August 14, 2012 Online Published: September 1, 2012

doi:10.5539/jsd.v5n9p42 URL: http://dx.doi.org/10.5539/jsd.v5n9p42

\begin{abstract}
The signatory countries of the Convention on Biological Diversity set the objective of halting the decline of biodiversity by 2010 , but as the target date arrived and passed, the status of biodiversity on the planet remained dismal. With the dawn of the UN Decade for Biodiversity at the Rio+20 Earth Summit in June 2012 and as the UN Biodiversity Strategic Plan moves forward, this article contextualizes biodiversity prospects in sub-Saharan Africa by examining the history of interactions between African communities and the environment, from the pre-colonial period to today. It provides a critical analysis of the current biodiversity conservation planning methodologies and pinpoints several inherent obstacles, including the neo-Malthusianism that dominates the thinking of certain wildlife experts.

Setting out an argument with far-reaching implications for the success of future conservation efforts all over the world, the author examines the basis of emerging conservation approaches in sub-Saharan Africa, focusing on the need to forge a more inclusive conservation practice and open up to the perceptions, representations and cultural universe of the Other.
\end{abstract}

Keywords: Sub-Saharan Africa, biodiversity conservation, planning methodologies, development, epistemology, neo-Malthusianism, representations, traditional ecological knowledge (TEK)

\section{List of abbreviations}

CAR: $\quad$ Central African Republic

ICA: Infrastructure Consortium for Africa

IEPF: $\quad$ Institut de l'Energie et de l'Environnement de la Francophonie

IUCN: International Union for Conservation of Nature

IUCN-CMP: IUCN Conservation Measures Partnership

UNEP: $\quad$ United Nations Environment Programme

UNESCO: United Nations Educational, Scientific and Cultural Organisation

WCMC: World Conservation Monitoring Centre

WRI: World Resources Institute

\section{Introduction}

In 2002, at the Johannesburg Summit on Sustainable Development, the 196 governments that ratified the Convention on Biological Diversity set the laudable goal of halting the decline of biodiversity by 2010, which the United Nations declared to be the International Year of Biodiversity. The purpose of this forceful gesture was to raise international awareness of the critical importance of diversity, communicate the cost of its loss to humans and engage the world population, especially young people, in the movement to protect all life on Earth. When the projected deadline came and went, a number of scientific articles were published outlining the marked increase in the pace of biodiversity loss since the 2002 announcement of the Conference of the Parties objective. These include Focus Biodiversité (2010), Nègre et al. (2010), Mauz and Granjou (2010), République française (2010), and Le Pestre (2011) to name just a few. 
A preliminary analysis of the reports published in 2010 reveals a unanimous acknowledgement of failure. The UN (2010) bluntly states that we have fallen short of the objective, set in 2002 by the governments of the entire world, "to achieve by 2010 a significant reduction of the current rate of biodiversity loss at the global, regional and national level as a contribution to poverty alleviation and to the benefit of all life on Earth." Innumerable signs indicate that the three major components of biological diversity continue to decline: genes, species and ecosystems. In a press release dated May 10, 2010, the United Nations asserted that "Governments have, on the whole, failed to achieve the objectives set by the Convention on Biological Diversity that aim to reduce the percentage loss of biodiversity." International organizations and, indeed, most countries on the planet confirm this finding. UICN-France (2010), for example, not only agrees that the objective has not been achieved but confirms that despite efforts made, the overall status of biodiversity has not improved in French territory and that pressure on biodiversity is as relentless as ever. The global actions taken were simply not up to the task.

With regard to Africa in particular, governments at a recent regional meeting acknowledged their collective failure to achieve the 2010 objective. They singled out sectors such as agriculture, fishing, economy and tourism for not taking the issues of biodiversity to heart. In many sectors not directly related to biodiversity and environmental issues in general, attempts to include biodiversity in strategies and programs have been fruitless (UNEP, 2010). Finally, the Secretariat of the Convention on Biological Diversity (2010) points out that "Africa continued to have the largest net loss of forests in 2000-2010. Wild species are being over-exploited for a variety of purposes in terrestrial, inland water and marine and coastal ecosystems. Bush meat hunting, which provides a significant proportion of protein for many rural households in forested regions such as Central Africa, appears to be taking place at unsustainable levels. In some areas this has contributed to the so-called 'empty forest syndrome,' in which apparently healthy forests become virtually devoid of animal life. This has potentially serious impacts on the resilience of forest ecosystems, as some $75 \%$ of tropical trees depend on animals to disperse their seeds."

The loss of biodiversity in sub-Saharan Africa has been engineered by a long stream of causes, including some of distant origin that are steadfastly ignored despite their ongoing relevance. Other, far deeper causes appear to be related to perceptions and representations of biodiversity conservation, as well as the meaning ascribed to certain key concepts that have not yet been subjected to in-depth debate, such as threat, conservation, and preservation and protection (Note 1).

In the lead-up to Rio +20 Earth Summit, one year into the United Nations Decade for Biodiversity, the current conservation situation in sub-Saharan Africa provides a number of telling lessons with wide applicability for future national and international efforts to protect and sustain the ecological health of our planet. The planning and management process embraced today around the world is hampered by shortcomings - particularly with regard to first-world bias and lack of input from certain groups of stakeholders - that the UN Strategic Plan for Biodiversity 2011-2020 would be wise to rethink if solid results are to be achieved at national, regional and international levels by the end of this decade.

\section{Chronicle of Rising Human Impact on Biodiversity in sub-Saharan Africa}

In sub-Saharan Africa, human impact on the environment can be divided into three periods: pre-colonial, colonial and post-independence.

In the first period, we are reasonably certain that resource appropriation was based essentially on subsistence agriculture (using shifting cultivation), hunting, foraging and gathering. Traditional "quantitative" sources about the sub-Saharan peoples before the twentieth century are not available, but demographers and historians estimate that prior to 1900, the annual growth rate of the population was less than $0.1 \%$. According to Diop-Maes (1993), around 1850-1870, after the losses related to the African slave trade, Black Africans numbered about 200 million. These people took full advantage of the fortuitous bounty of nature, adapting their lives to their natural environment and leaving minimal and fleeting traces in their search for sources of food. The limited-scale subsistence farming and livestock breeding they practised had a very minor impact on biodiversity, as did their hunting, gathering and foraging activities. Certain cultural practices - including initiation, rules and periodic prohibitions against entering certain areas - dictated and transmitted behaviour and attitudes concerning the appropriate use or protection of natural resources and environments. This was an era of abundance, as noted by explorer Henry Morton Stanley as he crossed areas teeming with game in 1874: "One day, I shot a giraffe and an antelope. The next day, five zebras. The next, two wildebeests, a zebra, four guinea-fowl...” (Saussus, 1952).

In 1885, the Berlin Conference divided Africa up into colonies, meting them out to the various European governments and enacting official rules for colonization. The colonial period was ushered in with the creation of major commercial concessions, including huge forestry concessions and vast domains dedicated to cash crops. 
Massive displacements ensued, with locals forced off the best lands in favour of trusts and colonizers. The shift to commercialization compromised the balance of the traditional agricultural system, which incorporated long fallow periods to give the land sufficient time to recover. Coquery-Vidrovitch (1985) points out that at that time in the Belgian Congo, the African peoples had almost no land while concession-holding corporations held absolute rights over $2310000 \mathrm{~km}^{2}$, just shy of the country's total area of $2345410 \mathrm{~km}^{2}$. Karsenty and Pierre (2005) explain that in the same period, France established a system of trading companies, to which vast concessions were granted. In 1899, an area equal to $70 \%$ of the future French Equatorial Africa was turned over to some 40 trading monopolies (each with its own region). The colony (which encompassed today's CAR, Chad, Congo and Gabon) was divided into 40 enormous territorial concessions covering some 700000 of the total $900000 \mathrm{~km}^{2}$. Rodgers et al. (2002) also note that under the British Empire, a huge portion of the forest estate in Eastern Africa was reserved before the First World War. Ward and White, cited by Dunaway (2010), mention that "while redistributing a majority of the most economically productive areas to Europeans, colonial states delimited African access to ancestral lands that had been used for diverse traditional activities." Dunaway (2010) also cites Wallerstein and Martin, who point out that "British policy summed up the philosophy of all the colonizers: 'What is wanted is surely a policy that would establish once and for all that $[\ldots]$ the ownership of land must be in the hands of the white races."

Moreover, ongoing attempts to convert the African peoples led to a blanket prohibition on "savage" traditional rituals, forcing underground some practices that could be beneficial to natural conservation. In the early 1920 s, the creation of the first protected areas - modelled on America's first national park, Yellowstone, which was created in 1872 to preserve nature for future enjoyment - exacerbated the precarity of the people's land tenure. This model, which prohibits human intervention in protected areas, is one of the credos of the Neo-Malthusians entrusted with the protection of nature: this is how the repressive power of the colonial authorities attempted to limit the loss of biodiversity.

With the advent of African independence, the initial intoxication of freedom triggered a hangover that played out in a protracted period of uproar, political upheaval, civil war, genocide and authoritarian civil or military regimes. For many countries in Black Africa, violence and poor governance dominated the post-independence decades. After independence, despite the ongoing social and environmental fallout caused by the scramble for Africa, mention was never made of the opportunity to return any rights to the people. The concession model survived the political changes in the form of multinational agricultural and forestry companies and national economic elites, and continued to marginalize rural dwellers and indigenous peoples, dismantle traditional land ownership regimes, limit access to resources and upend agricultural production methods, reducing fallow periods. Now, at the beginning of the $21^{\text {st }}$ century, the worst is yet to come, with the emergence of a new type of super-concession granted to multinationals from emerging countries in the name of biofuel production.

At the same time, with cities spreading inexorably like a powerful and ceaseless tide immune to all planning, the high rate of urbanization - which had promised a significant decrease in the dependence on wild back-country natural resources - has paradoxically become a major driver of biodiversity decline. The combination of accelerated, uncontrolled urbanization, demographic growth and the emergence of new modes of consumption has turned out to be an explosive cocktail for the conservation of biodiversity. A significant cultural shift toward new eating habits has widely extended the consumption of bush meat among urbanites and new urbanites, even among ethnic groups who did not traditionally partake. This phenomenon, coupled with the exponential increase in the demand for energy-wood - especially charcoal - accelerates the loss of biodiversity, as sub-Saharan Africa has the world's lowest rate of electrification, with only $23.6 \%$ of households having access to electricity. Several recent studies confirm these trends; see in particular Africa Science (2007); Ape Alliance (1998); Bennett et al. (2002); Binot \& Cornelis (2004); Brashares et al. (2001); Cowlishaw et al. (2005); Devers et al. (2006), De Vos (1977); FAO (2007); ICA, (2008); Mainka \& Trivedi (2002); Musibono et al. (2010); IEPF (2006); Paluku-Mastaki (2005); TRAFFIC (2010); and Wilkie \& Carpenter (1999).

The international community's awakening to this unprecedented disappearance of biological diversity, expressed formally at the Stockholm Conference in 1972, revealed the pressing need to develop a Convention on Biological Diversity. Taking the conservation of biodiversity as its objective, the Convention was opened to signatures on June 5, 1992, at the Earth Summit in Rio de Janeiro. At present, it has been ratified by every sub-Saharan African nation. And yet despite the emergence of new inclusive categories of protected areas, the momentum of biodiversity decline in this region remains unchecked.

\section{The Biodiversity Conservation Planning Process in sub-Saharan Africa}

The legally binding Convention obliges the signatories to develop national strategies and action plans for biodiversity conservation, but if the goal is to check or even reverse the trend of biodiversity loss, there is an 
urgent need to examine the development process for these strategies and plans, as well as their implementation in sub-Saharan Africa.

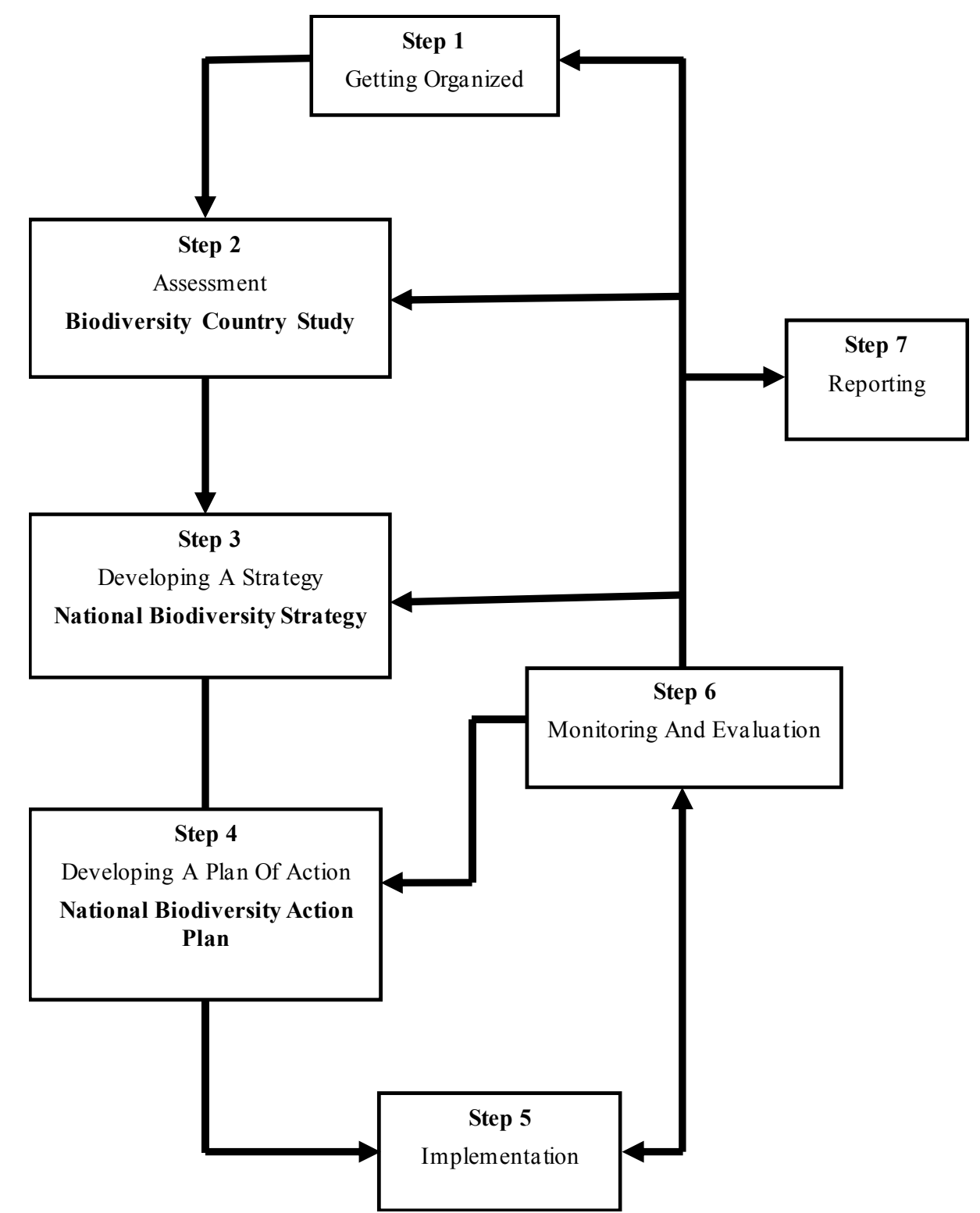

Figure 1. Basic steps of biodiversity planning and its relationship to the planning tools: a cyclical and adaptive process (IUCN, UNEP \& WRI, 1995)

The IUCN, the UNEP and the WRI (1995) published a national biodiversity planning guide that rapidly gained sway as the methodological bible for biodiversity conservation planning among the Convention's signatories, including those in sub-Saharan Africa. Three biodiversity planning tools defined in the lexicon of terms and practices for the Convention and related resolutions are the cornerstone of the method promoted by the guide: biodiversity country study, national biodiversity strategy and national action plan. These tools are to be used in a participatory, adaptive and cyclical manner.

The country study is designed to gather strictly scientific information on the country's biodiversity status and trends. The national strategy analyses the data and descriptive information in the country study and establishes general goals and objectives. The national action plan identifies the public and private organizations and groups that will carry out the activities outlined in the strategy, the locations or areas where they will take place and the means and resources that will be used. It also establishes a timetable (see Figure 1). 
Yet in most French-speaking sub-Saharan African countries (Note 2), the participatory aspect of the biodiversity action plan and strategy planning steps is little more than myth, falling far short of the Convention's participation goals. In the country study step, all data on biodiversity were gathered by scientific researchers, and the initial draft strategies and action plans were developed exclusively on the basis of these data.

But how can we describe an environment and analyse the changes it is undergoing without engaging the knowledge of the people who live in it? Local Traditional Ecological Knowledge (TEK) often provides the best assessment of the real biodiversity situation on the ground. As well as yielding relevant information on the ecological, economic, social and cultural aspects of biodiversity, this type of knowledge also offers information of an intrinsic nature.

Despite this, TEK is largely ignored by the scientific elite and has been spurned from the beginning of the planning exercise, due to the conviction that what comes from the West is objective and therefore more valid.

In addition, data from the participant lists for the various biodiversity strategy planning sessions and planning committee reports held in French-speaking sub-Saharan African countries indicate that women never make up more than $20 \%$ of participants, despite the fact that women perform virtually $90 \%$ of all natural resource management-related activities in rural areas. It is unreasonable to speak of a fully participatory process when in the majority of the planning sessions, most stakeholders have not been involved at every stage of the process, i.e., from organization through to report writing (Kasisi \& Jacobs, 2001).

The planning scheme that has actually been adopted combines a linear intervention method with compartmentalized and disconnected sequences - called stages here - that make it difficult to engage in what Le Moigne (2008) calls the endless process of inter-retro-action. Of the six national biodiversity strategies adopted by French-speaking sub-Saharan African nations, not one has updated the stages of its planning process. Yet since then, several new environmental, economic and social issues have emerged that have completely upended the overall portrait of biodiversity since the time these strategies were originally developed.

One need think no further than critical emerging issues such as climate change, the high rate of poorly planned urbanization, the growth in the demand for energy-wood, the appearance of new zoonoses, the propagation of invasive exotic species, the advent of new social and economic rights for rural populations, and unpredictable factors such as political instability and the uncontrolled trafficking of weapons of war in biodiversity hotspots in the grip of armed conflict. All these questions are unfortunately dealt with today exclusively by technocrats and environmentalists in isolation, with no consideration for the people who are intimately affected by and interested in these synergetic matters, such as rural people, indigenous groups, women, etc.

\section{Logical Framework as a Logical Approach to Designing Biodiversity Conservation Projects}

Most biodiversity action plan and strategy planning exercises in French-speaking sub-Saharan African countries were conducted using the Logical Framework (log frame) approach. The log frame approach is a method than can be used to analyse biodiversity-related problems on the basis of site inventories and biodiversity surveys. It can also be used to develop and analyse the biodiversity-related action objectives related to the problems analysed. 


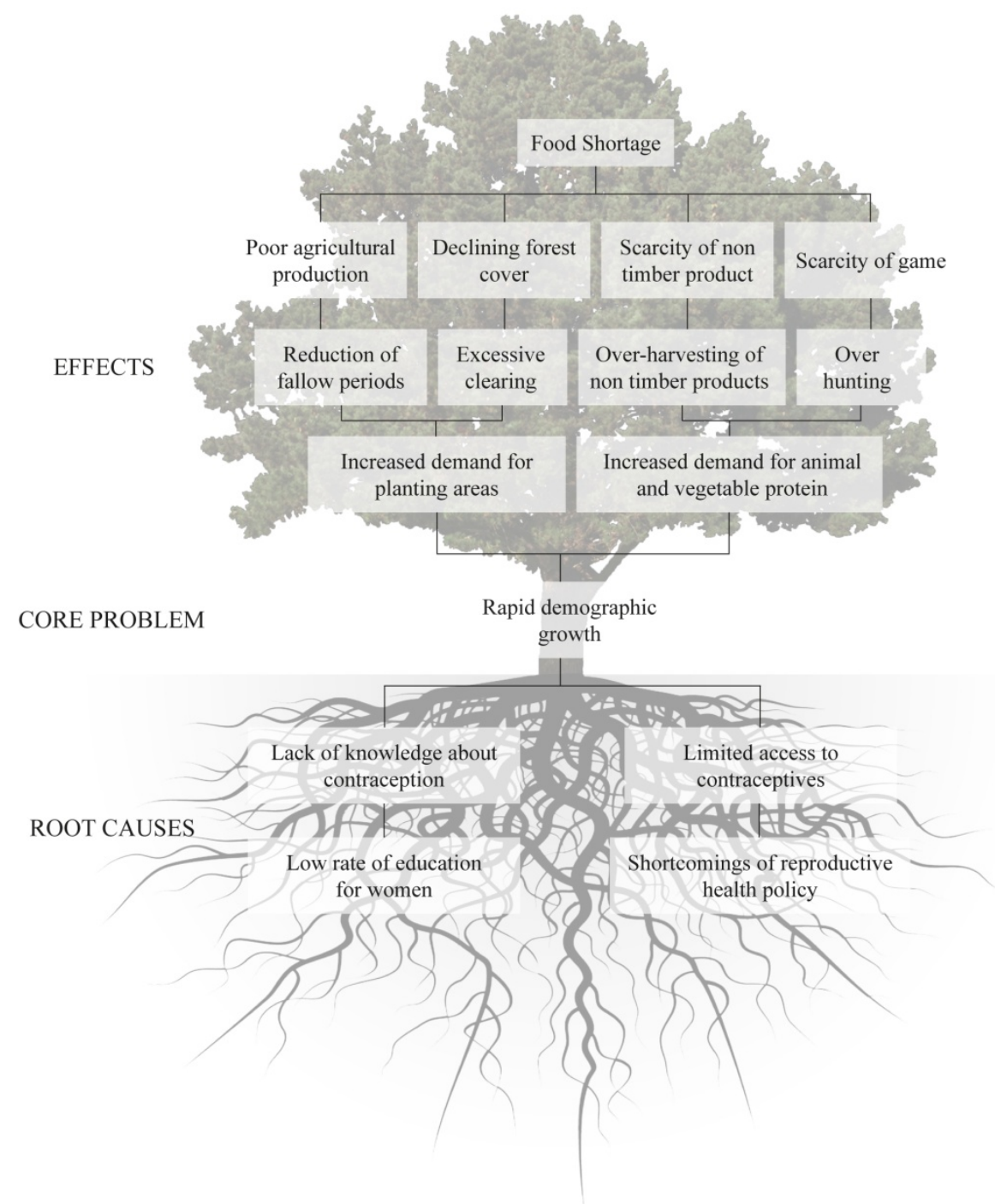

Figure 2. Problem tree

Problem analysis consists of establishing cause-and-effect linkages between the negative aspects of an existing situation and presenting the results as a problem tree (Note 3), with the effects of a given problem indicated above and the causes below (Kasisi \& Jacobs, 2001). See Figure 2.

The inclusion of these problems in the log frame is not based on their objective reality but on the fact that they are designated as problems during the identification process, which is itself subject to negotiations among diverse interest groups that do not all necessarily have the same powers of persuasion or influence. The power relationships in the negotiation process are rarely balanced in favour of the most vulnerable parties, so many problems put forward as important and very real by some parties never achieve public recognition. 
PROBLEM DIAGRAM

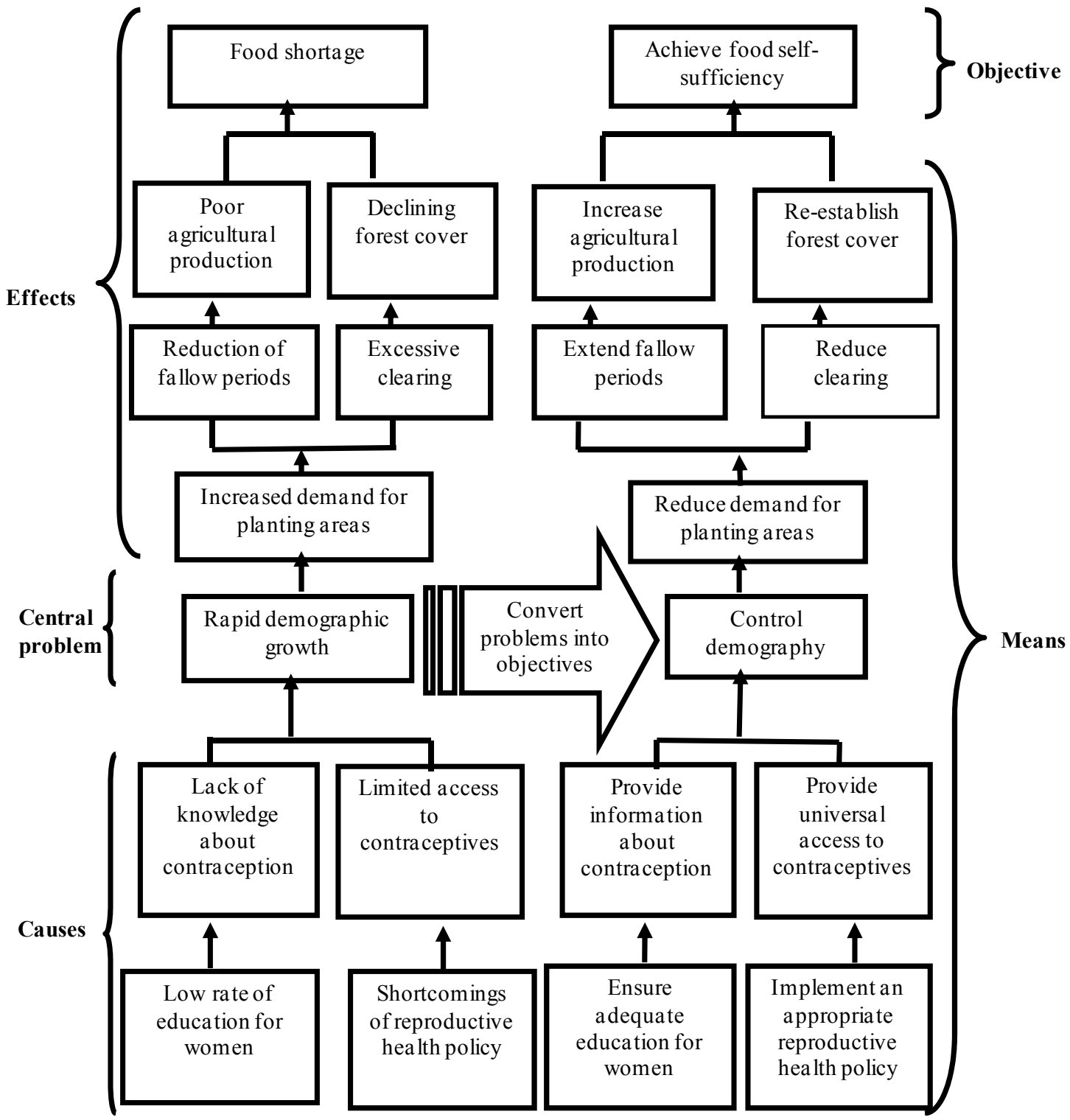

Figure 3. Conversion of problems into objectives

The objectives are established by converting the negative conditions of the problem diagram into positive conditions. All the positive conditions achieved are presented in a new objective diagram that depicts the "means-end" hierarchy (see Figure 3). Finally, on the objective diagram, different "sets" of similar objectives are called strategies.

Although using a log frame to indicate problems and establish the causal links between negative factors offers the advantage of presenting the overall situation in table form, the various elements are necessarily presented in a linear structure. This contributes to the impression that biodiversity management issues can be considered as a string of minor interconnected problems. It is clear, however, that these problems are dependent on social, political and economic forces that extend beyond the local context (e.g., globalized markets, cultural adaptation) but are not independent from it. To pursue the problem analysis to greater depths, an ever-increasing number of external variables need to be taken into account. This presses the analytical capacity of the log frame model beyond its theoretical limits (Kasisi \& Jacobs, 2001). 
In practical terms, for most sub-Saharan African countries, the translation of the Convention's requirements into conservation actions runs into problems on several different levels. For most of these countries, the planning scheme proposed by the IUCN, the UNEP and the WRI is not flexible enough to take local complexities into account, despite the iterativity among the design stages. For countries that used the objective-oriented project planning method (OOPP) or log frame, the use of isolated actions and the disjointed way the problems were selected led to an impasse, reflected broadly in the failures underlined in the various reports. All this reveals a clear need to incorporate the notion of complexity in the explanatory field of the environment as object.

\section{Day-to-Day Biodiversity Management or the Triumph of neo-Malthusianism}

A number of the wildlife experts at the helm of so-called conservation programs and projects are unfortunately the product of a culture of scientific education based on specialization and compartmentalization, and prey to what Edgar Morin (2004) calls a paradigm of disconnection. When these experts stray beyond biology to deal with social issues, they tend to apply the climax community model, which they view as the ultimate good in any biological system. Like Ramade (1987) and many other biologists, they cheerfully espouse the thesis of Malthus, identifying the demographic growth of humans in the South as the number-one catastrophe affecting humanity and pointing out that the great northward march of the starving has clearly begun. This approach - based on the notion of carrying capacity or load limit imposed by the intangible laws of nature - is drawn from the concepts of plant and animal population biology, but attempting to project concepts and models drawn from the study of other species on to humans twists and perverts the outcome, with heavy consequences. It generally results in a quasi-autistic incapacity to read and interpret facts, thoughts and feelings, leading to a selective intellectual blindness that will undoubtedly prolong the status quo for a long time. This is the line of thinking that left us with the distasteful legacy of Duvigneaud (1980) who, to support his idea that Zero Population Growth (ZPG) will help reverse the pace of degradation of the biosphere, claims that infanticide and abortion have always been the most effective means of birth control, going on to recommend several human population control measures including the sterilization of fathers and mothers and other drastic coercive measures that he feels should be made mandatory. This is not far removed from the ideas advanced in the 1990s by one influential and highly placed conservationist who identified ways to "reduce" the African population in order to allow elephant populations to recover, or the remarks of certain ecologists who cynically said that tsetse flies are the best game wardens in Africa!

The works of Ramade, Duvigneaud and other high priests and glorifiers of neo-Malthusianism (Note 4) are the university textbooks studied by most of the French-speaking ecologists operating in Africa. In sub-Saharan Africa, since the 1960s, solutions have been advanced and "imposed" by biologists to halt the decline of biodiversity, and yet the pace of the decline is ever-increasing. At the same time, the new generation of Anglo-Saxon ecologists working in the field of biological diversity have adopted a more open approach, having awoken to the need for collaboration among the various disciplines and acknowledged the complexity of the problems and the applicability of global theories. This is definitely not unrelated to the fact that in the Anglo-Saxon world - including Québec (Note 5) - the discipline of conservation biology developed quite early on. These ecologists were most likely exposed during their education to the thoughts of renowned biologist E. O. Wilson (1992) who said that "What is urgently needed is knowledge and a practical ethic based on a time scale longer than we are accustomed to apply. An ideal ethic is a set of rules invented to address problems so complex or stretching so far into the future as to place their solution beyond ordinary discourse... What is good for individuals and societies at this moment might easily sour ten years hence, and what seems ideal over the next several decades could ruin future generations... To choose what is best for both the near and distant futures is a hard task, often seemingly contradictory and requiring knowledge and ethical codes which for the most part are still unwritten." Paradoxically, this echoes the very principles of complex thought that have been thoroughly developed by French-speaking philosophers and sociologists.

Cheminade (2007) points out that since the appearance of humankind on the planet, the trend has always moved in the same direction: permanent interaction between human societies and biophysical environments, and increasing human encroachment on the environment, through both demographic growth and technological progress. This relationship between humankind and nature is not and has never been static. It is a dynamic balance in constant upheaval due to the political, economic and social transformations human societies undergo. For humanist ecologists, the thinking human being is able to improve the management of the biosphere by discovering the laws of its development and, based on these discoveries, introducing new methods of production that advance the conditions of human life for everyone and, by extension, increase the planet's capacity to support. 
In sub-Saharan Africa, the living-conditions/demographics/natural-resources equation always moves in the direction of improving environmental management when measures are taken to advance the equality of the sexes and the education and empowerment of women. These measures effectively contribute to actual reproductive control, unlike the coercion-based approaches put forward by most neo-Malthusians. Indeed, such approaches have demonstrated their limits everywhere they have been tested (Note 6).

\section{Quest for Common Sense in the Reference Concepts of Biodiversity Conservation}

For several decades now, extensive efforts have been devoted to developing new approaches to slow down or even halt the decline of biodiversity. Significant sums have been allotted to a whole series of projects designed according to these approaches in sub-Saharan Africa. They all take, as their basic principle, the reconciliation of the needs of biodiversity conservation with those of sustainable economic development. But convincing examples of the success of this reconciliation are hard to find. Although these new approaches do reflect some advancement, especially in terms of the consideration of socio-economic needs and the participation of local populations, in hindsight they all harbour a basic weakness that largely explains their disappointing results in practice. These approaches rely on a conceptualization of environmental problems that is predicated on the notion of threat, but while this responds widely to factual concerns, its applicability has not yet been tested or proven. It is no coincidence that the literature and the various legal documents and texts on biodiversity refer exclusively to threat categories. Our point is not to question the categorization of threats, which comes down to a form of tautology, but to highlight the lack of debate on the applicability and commonsensicality of the very notion of threat in the literature on biodiversity conservation. This debate is a prerequisite to responsible engagement in the process of biodiversity conservation.

One recent example where people's lives have been at stake - still currently in the news - is the Kahuzi-Biega National Park in the Democratic Republic of Congo. The park was created in 1970 under the rule of the dictator Mobutu, with an initial area of 60000 hectares exclusively located in the high-altitude section. The main objective of its creation was the preservation of Eastern lowland gorillas (Gorilla gorilla graueri). In 1975, the area was expanded to 600000 hectares with a 540000 extension in the low-altitude forest. To connect the existing park to the new extension, the country's authorities created an ecological corridor without consulting the local residents. The ecological corridor is in fact a strip of land occupied by farmers who had purchased the land deeds of old colonial farms. According to governmental and ecological organizations, the corridor would facilitate a new genetic exchange among the large mammal populations of the two parts of the park. The farmers and local populations claim, however, that in living memory, large mammals have never travelled along this strip between the two parts of the park. For these farmers, the ecologists' argument is a simple sophism. Right or wrong, the farmers assert that the socio-economic benefits of their activities are helping to consolidate peace in the region, which has been struggling to achieve political stability and security. Several attempts to evict the farmers encountered fierce resistance on their part. They armed their flock attendants with combat weaponry and drew support from Rwandan militias operating in the region (several of which were involved in the Rwandan genocide), as well as members of the Congolese army. Where exactly lie the truth and certainty about the threat of genetic integrity for the large mammals of Kahuzi-Biega? The wildlife experts are probably right to believe that only an ecological corridor will guarantee the genetic viability of these mammals, but they have not yet succeeded in clearly demonstrating the threat and have come nowhere near convincing the farmers of the need to abandon their land for the benefit of the park. In reality, the strip of land is still occupied by the farmers, and the ecological corridor is nothing more than a theoretical construct in the park's General Management Plan.

Is the concept of threat "objective"? Is its weight not determined by the party that perceives it, believes in it, or claims to see it? Threat is definitely subjective in the sense that it relies on perceptions of reality. But to know whether or not our perceptions are valid, we have to establish criteria, and these criteria can only be based on other perceptions, which may not necessarily be reliable either. To be credible, the concept of threat must submit to the test of certainty. Jolivet (1962) notes that there are two forms of certainty: scientific certainty and philosophical certainty. The former exists solely through the reduction of laws or formulas to empirical or sensory evidence (that is, to the sensory being), and the second, through the reduction of philosophical assertions to rational evidence, which is the first principle of practical reason (the principle of contradiction). Which of the two certainties is required to confirm the truth of the threats to biodiversity in this case? The answer remains to be seen.

IUCN-CMP (2010) defines "direct and indirect" threat as being (human) activities or processes that have caused, are causing or may cause the destruction, degradation or impairment of biodiversity or natural processes. It also lists the different threat categories, although the relevance of some of them is debatable. Comments on the IUCN-CMP blog (Note 7) concerning the definition - not the meaning - and the categories of the threats explore 
this issue. Will objective understanding or subjective beliefs prevail? One question-comment from Lee C. posted on the IUCN-CMP blog on May 4, 2011, relates to this notion of threat and raises the question of whether "objective" understanding or "subjective" beliefs will hold sway when we try to legitimize a threat. Perception plays a fundamental role in the achievement of understanding, and yet perception is heavily influenced by the perceiver's personal culture and experience. Russell (1990) also established a connection between beliefs and perception, asserting that from the psychological point of view, any belief can be deemed to be inferred when it is caused by other beliefs, however illogical the inference may be. The beliefs most clearly not caused by other beliefs are those that result directly from perception. From this he proposes that beliefs rooted in perception be accepted unless there are positive reasons to reject them.

\section{Perceiving and Decoding the Cultural Universe}

We know that the relationship between human beings and their environment is determined by what they know about the environment. Our intervention in the environment is consequently conditioned by our knowledge of it. The current state of the environment reveals two interrelated aspects of our various environmental protection efforts. One relates to the objectivity of our view of the environment, and the other, to our methodological legitimization of our intervention processes based on that view.

Is observation a neutral act that allows us to grasp the objective reality of the environment as object that we are observing? Is it possible for us to transcend the paradigm of disconnected thought that has controlled and continues to control Western thought with regard to the way we intervene in the environment?

As to whether we can claim to achieve neutral observation of the environment as object, the evidence is clear. Vitrac (2005) suggests that the human observer of the environment as object is a system with an awareness that gives it a clearly defined identity and allows it to maintain a relationship (perception and actions) with other systems (peers, biodiversity, the environment, etc.). This relationship is only possible because of the connection between the human-being-system's awareness and its internal memories through another axis that Vitrac called the "axis of thought" or "interior reflection." These internal memories condition the human being's perceptions and, ultimately, actions. As Egea (2005) points out, knowledge operates through the selection of meaningful data and rejection of meaningless data by separating (distinguishing or disconnecting), combining (associating or identifying) or prioritizing (principal, secondary) and controlling (based on guiding concepts). These operations are directed by the principles of thought organization that govern our vision of the world at a subconscious level. We live and make decisions under the influence of the principles of disconnection, reduction and abstraction which together constitute a "paradigm of simplification." This disconnected thought guides our decisions. Likewise, Morin (1990) affirms that for several centuries, the whole of Western thought has been subjected to the paradigm of simplification that separates what is linked (disconnection) and condenses what is diverse (reduction). In this way, we have disconnected the biological human from the cultural human and reduced the latter to the former, or vice versa. But one cannot exist without the other. They are one and the same, albeit with some differences.

Since the human-being-system's awareness is related to its internal memories, Vitrac (2005) insists that the peoples of the Earth do not share the same perception of the environment as object and are even less likely to see eye to eye on the best forms and processes for biodiversity conservation. Conservation cannot be fully effective unless it takes into consideration what Philippe Descola (2008) calls the plurality of the intelligences of nature. There are as many perceptions of the world as peoples on the planet. Ergo the need to take account of cultural diversity and these complex relationships with biodiversity, including our very understanding of the concept of "nature." Chevassus et al. (2004) suggest promoting a "culture of debate" whenever the state of nature at a given time, and especially its future, cannot be claimed to be the result of scientific "laws" and therefore demands input from the conceptions and expectations of all stakeholders.

Understanding differences of perception may also increase our understanding of the rational bases for the attitudes that arise from these perceptions - a critical point, as it is on these bases that people determine how the environment and its resources will be managed. But taking opposing perceptions into account demands that we first access them. In sub-Saharan Africa, access may depend on understanding different forms of expression, including culture through artistic expression, such as graphic art, visual arts, music, dance, etc., and literature, especially fairytales, proverbs, sayings, myths and legends, adages and maxims. Certain verbal linguistic and paralinguistic forms - such as expressive reduplication, the use of pleonasm and the tonic accent - also constitute inroads for understanding. Consider these two Swahili proverbs:

- Haraka haraka haina Baraka, which means "hurry, hurry has no blessings."

- Pole pole ndiyo mwendo, which means "slow, slow is the way to go." 
Recently in a radio interview, a Congolese doctor laughingly told a French journalist, with reference to the AIDS campaign in his country, "You know, in our countries, words are always double. Maya-Maya, Poto-Poto. You have to always repeat things to be sure people understand." In most Black African languages, this peculiarity of expressive reduplication, like the tonic accent on elongated vowels, is proportional to the importance of the message to be communicated.

A lot of information can be gleaned from non-verbal language. Gulea (2001) notes to this end that the system of verbal communication works with a non-verbal system that may be even more "telling". Before even opening their mouths, people provide reams of information through their behaviour (gestures, faces, looks, wearing of artefacts and sometimes even the production of bodily sounds).

Finally, despite the fact that religious practices such as initiation rites, sanctification and symbolism offer solid clues to understanding cultural context, a clear pre-requisite for improving biodiversity planning, very few sub-Saharan wildlife experts demonstrate any interest in traditional religion, fairytales, proverbs and myths.

We know, however, that respect for biological diversity demands respect for human diversity. Both elements are fundamental to mutual conservation. The key to creating forms of development that are sustainable and in harmony with the needs and aspirations of every culture is to abandon patterns that undermine the lives and perspectives of those cultures. Tolerance and reciprocal respect for cultural distinctiveness are indispensable conditions for increased mutual understanding among the world's peoples and recognition of our common humanity (UNESCO \& UNEP, 2003).

\section{Reforging the Practice Based on an Alliance of the Two Forms of Knowledge}

Since humankind's relationship with the universe is determined by what we know about that universe, the question to ask is what tools, pathways and means are available to help decipher the nature of our knowledge of the world, in order to verify its compliance or non-compliance with the practices used to manage the environment. We know that we have so far failed to place sufficient emphasis on the role of value systems and different perceptions in the process of conserving biological resources and on the power relationship between local traditional knowledge and classic scientific knowledge and their potential complementarity.

It is increasingly unacceptable to describe the environment and analyse its changes without the input of local knowledge. Such knowledge may be general or very specific, ordered according to different principles, based on decades or even centuries of observation and verified through years of trial and error. Western science and those who practise it in the field of biodiversity conservation in sub-Saharan Africa are often dismissive of the results of other cognitive methods, particularly so-called "traditional" knowledge. In traditional ecological knowledge, an object has multiple meaning. It simultaneously incarnates a material value, a symbolic value (totem), a cultural value (work of art), an economic value and also an ecological value (role in an ecological pyramid) (Kasisi \& Jacobs, 2001). Many field researchers consider the combination of traditional knowledge with the specialized knowledge of foreign or national researchers to be more powerful for understanding reality than either of the two types of knowledge taken separately (Christie \& White, 1997).

\section{Conclusion}

Jon Hutton (Note 8) (2010) sets out three reasons to explain the failure of the 2010 objectives. First, he feels that the international community failed in the definition, funding and implementation of the policies to wipe out biodiversity loss: "We have been insufficiently strategic in the design, funding and implementation of policies to tackle biodiversity loss, and we have not adequately monitored our successes and failures."

Second, he believes that the short-term interests of land conservation have been allowed to supplant the long-term benefits drawn from ecosystem services: "Biodiversity has not been mainstreamed into agriculture or other key drivers of land-use change."

Finally, he asserts that the actual meaning of biological diversity and the need for its preservation have not been fully explained: "Despite some gains, we have still not persuaded the public or decision-makers of the importance of biodiversity and the urgency of action. We are very poor at explaining what biodiversity is and justifying why it is important."

These three reasons provide multiple and synergistic explanations for the world's failure to stem the tide of biodiversity loss.

The drawing board on which today's biodiversity policies are designed, at the global, national and local levels, is built of our perceptions of the intertwining and interactions among the economic, political, social, national, ethnic, religious and mythological processes that weave our planetary destiny (Morin et al., 2003). Unfortunately, 
the education systems that trained most of the elites responsible for developing and implementing biodiversity policies have not felt the need to foster minds able to grasp the fundamentally global nature of problems and understand their complexity. Teaching systems continue to parcel out and break apart knowledge that should be connected, training one-dimensional and reductive minds that favour a single dimension and neglect the others. We are facing a vital urgency to "educate for the planetary era," which demands three interdependent reforms: reform of our modes of knowledge, reform of thought, and reform of teaching (Morin et al., 2003). Shifting to this paradigm will also allow us to avoid the triumph of neo-Malthusianism with regard to biodiversity conservation in sub-Saharan Africa.

Concerning the connection between religion and environmental protection, many sub-Saharan wildlife experts display a disconcerting ignorance when they claim that religious intervention in the management of space and natural resources is a strictly non-Western affair. In Europe, for example, wetlands were often left undeveloped for centuries due to a vision inherited from Descartes, but also shared by the Physiocrats and by all Roman Catholic groups at the time, that considered the "organic" to be the vehicle of turpitudes, amoral behaviours and demonic practices, a vision in which man's control over nature was seen as the embodiment of God's ineffable plan (Sajaloli, 2007).

A number of African initiation practices offer a glimpse into the knowledge that has moulded human behaviour over the course of time and established the ethical standards of the society, directing its use of natural resources and the environment by means of very strict rules regarding the balance of nature. Adapting these practices to biodiversity conservation programs could contribute to the protection and sustainable use of resources and threatened species in certain protected areas. Overseen by the initiates, these practices would offer a clear advantage by minimizing the repercussions inherent in abrupt acculturation which entails both deculturation (loss of cultural traits) and exogenous enculturation (assimilation to a new culture, especially one imposed by migration and globalization). They would also offer a form of re-culturation to foster the reappropriation of the original culture (Kasisi, 2010 in press). Fortunately, some regional ritual practices, such as the Makishi Masquerade in Zambia, are being recognized as intangible cultural heritage by UNESCO. It is timely and in fact imperative, in sub-Saharan African today, to pursue the rehabilitation of traditional environmental ethics rooted in local cultures, which could be achieved by adapting the legislative and institutional framework and creating relevant educational, awareness and communications programs.

To return to Hutton's second reason, we need to envisage the long-term benefits of ecosystem services, rather than reducing them to short-term imperatives - a requirement of the most destitute - so that the right solutions today do not become insoluble problems tomorrow. To be more inspiring and, more importantly, to reflect objective reality, the biodiversity conservation planning exercise should include strategic reflection and project its actions over the long term instead of couching them exclusively in the discourse of urgency. There is a critical need to develop an approach that can anticipate global trends and formulate strategies that reflect those trends, especially in local contexts. The future must not appear to be inevitable. It must be built step by step. Unfortunately, in sub-Saharan Africa, most ecosystem management actions respond to imperatives of urgency that leave very little room for manoeuvre. Using long-range planning to guide the development of strategies and action plan would transform the process into a collective intelligence tool capable of mobilizing alternative solutions. The process should also seek to clarify the crucial issues of the future, especially by conducting a broader examination of economic, social, environmental and cultural changes and their repercussions over time. Finally, relinquishing short-term land conversion interests in favour of the long-term benefits drawn from ecosystem services requires a fair and equitable sharing of the tangible economic benefits among the different stakeholders. It is unrealistic, however, to imagine that the rural people and aboriginals who have been marginalized by the big concessions will be able to achieve or even spearhead a fair division on their own. The communities of sub-Saharan Africa offer a textbook case of the problem of divvying up the sacrifices and benefits related to biodiversity.

With regard to Hutton's final reason - the difficulty of clearly communicating the value of biological diversity and the need to preserve it - the challenge is enormous. Some lessons may be learned from the European attitude to biodiversity as revealed in the informative results of the most recent Eurobarometer survey, carried out in February 2010 (Eurobarometer, 2010). For Europeans, who are blessed with high performance communications and information infrastructures at the service of conservation awareness (television, radio, internet, school system, etc.), only $53 \%$ very much agreed that biodiversity is indispensable for the production of goods such as food, fuel and medicines; $33 \%$ rather agreed while $10 \%$ disagreed. Whether biodiversity is essential in tackling climate change: $50 \%$ very much agreed; $32 \%$ rather agreed and $11 \%$ disagreed. Whether Europe will get poorer economically as a consequence of the loss of biodiversity: only $45 \%$ very much agreed; $31 \%$ rather agreed while $16 \%$ disagreed. 
In sub-Saharan Africa, how can we begin to engage the people's support for the cause of biological diversity when they consider themselves to be socially, politically, economically and even culturally marginalized by the cause itself? Of course, there has been notable progress in the last two decades with the emergence of new approaches, including community management of forests, community conservation, participatory management and so on. Nevertheless, it would be illusory to imagine that the response elicited by these approaches is enough on its own to halt the decline of biodiversity. Effective participation with equitable representation of all stakeholders is the Achilles heel of the biodiversity conservation planning process and the concretization of sustainable management programs. Participation both garners support from the citizenry and establishes a better informational base that combines local knowledge and the plurality of values. When democratic space is expanded through upward, downward and horizontal exchange, the process itself turns into a powerful unifying tool that fosters communication (Kasisi, 2010). In sub-Saharan Africa, a few natural resource co-management experiments have generated positive results. Most of them placed equal emphasis on the following objectives: dissemination of information and reinforcement of awareness of the importance of biodiversity and the need to conserve it; adaptation of the political and legal framework to integrated, participatory management of ecosystems; facilitation access to credit; reinforcing of the capacities of all actors - local communities, extension workers and the staff of protected areas; ensuring participatory monitoring and evaluation of ecosystems. Since new technologies are increasingly available, even in deepest sub-Saharan Africa, it would be beneficial, following in the footsteps of other world regions, to use them to create a network of lessons learned, best practices, and innovative ideas for biodiversity conservation. This network could, in turn, connect with other existing networks on the planet to exchange ideas, thereby benefitting from the latest lessons learned in the field.

Information campaigns - often falsely called awareness campaigns - are unfortunately lost in a multi-input environment where the people's more pressing and urgent problems do not allow them to stop for a single moment to consider the messages the campaigns are attempting to transmit. A true awareness campaign cannot under any circumstances be comprised of a unidirectional monologue. It must take the form of a fair and honest exchange of opinions among the stakeholders. In addition to openness to the other, it demands a confluence and emulation of perceptions and different forms of knowledge. Unfortunately, the urge to light upon an immediate solution at any cost rather than ferret out a promising longer-term direction results in facile responses. And since human inhabitants are often perceived to be a "threat" to biodiversity, with no presumption of innocence, wildlife experts tend to hear them only through the filter of this prejudice, blocking any possibility of real dialogue.

The conservation of biodiversity is a decisive issue for the future of humankind. The importance of the ecological services provided by biodiversity has been proven beyond a doubt, particularly in terms of regulating the major biogeochemical cycles that affect the global environment and the economic and socio-cultural benefits they generate. To be intelligent, the debate on design and implementation cannot be the exclusive purview of specialists and decision-makers. We have an opportunity now to acknowledge our failures and commit to real change. As the UN Decade for Biodiversity begins and the world comes together once again at the United Nations Conference on Sustainable Development, we must insist on a transdisciplinary approach, opening up to all stakeholders and expanding to areas of reflection dedicated to the specific fate of humankind as well as those that focus on the health and future of nature. It is only from this perspective that we can begin to envisage slowing or reversing the process of biodiversity erosion in our world.

\section{References}

Africa Science. (2007). Congo Gorilla Killings Fuelled by Illegal Charcoal Trade. Retrieved from http://www.africascience.blogspot.com/2007/08/congo-gorilla-killings-fueled-by.html

Ape Alliance. (1998). The African bushmeat trade. A recipe for extinction.

Bennett, E., Eves, H., Robinson, J. G., \& Wilkie, D. (2002). Why is eating bushmeat a biodiversity crisis? Conservation in Practice, 3, 28-29.

Binot, A., \& Cornelis, D. (2004). Synthèse bibliographique du secteur « viandes de brousse » au Gabon. Rapport CIRAD-EMVT. N 04- 14.

Boesten, J. (2007). Free Choice or Poverty Alleviation? Population Politics in Peru under Alberto Fujimori. In European Review of Latin American and Caribbean Studies 82, April 2007. 3-20.

Brashares, J. S., Arcese, P., \& Sam, M. K. (2001). Human demography and reserve size predict wildlife extinction in West Africa. Proceedings of the Royal Society of London Series B: Biological Sciences, 268, 2473-2478. http://dx.doi.org/10.1098/rspb.2001.1815 
Brown, O., \& Kasisi, R. (2007). Renforcement de la capacité de l'ICCN à la gestion et la résolution des conflits lies aux ressources naturelles dans le Parc National de Kahuzi-Biega. République démocratique du Congo. International Institute for Sustainable Development (IISD).

Cheminade, J. (2007). Pour une écologie humaine. Retrieved from http://www.cheminade-le-sursaut.org/IMG/pdf/cheminade-2007-environnement.pdf

Chevassus et al. (2004). Biodiversité et changements globaux. ADPF.

Christie, P., \& White, A. T. (1997). Trends in development in coastal area management in tropical countries: from central to community orientation. Coastal Management, 25, 155-181. http://dx.doi.org/10.1080/08920759709362316

Convention on Biological Diversity. (2010). Biodiversity in 2010. Global Biodiversity Outlook 3.

Coquery-Vidrovitch, C. (1985). Afrique noire: permanences et ruptures, Paris, Payot.

Cowlishaw, G., Mendelson, S., \& Rowcliffe, J. M. (2005). Evidence for post-depletion sustainability in a mature bushmeat market. Journal of Applied Ecology, 42, 460-468. http://dx.doi.org/10.1111/j.1365-2664.2005.01046.x

Devers, D., \& Vande Weghe, J. P. (2006). Les forêts du bassin du Congo. État des forêts 2006. Kinshasa. PFBC.

De Vos, A. (1977). Le gibier dans l'alimentation: Son importance en Afrique et en Amérique du sud. UNASYLVA, numéro 116, 1977.

Descola, P. (2008). A qui appartient la nature? In La vie des idées.fr. 11.

Diop-Maes, L. M. (1993). Histoire de la population de l'Afrique noire du néolithique au milieu du $20^{\mathrm{e}}$ siècle. Faits, méthodologie et calculs. Revue ANKH n 2, avril 1993, pp. 164 - 199.

Dunaway, W. A. (2010). Nonwaged peasants in the modern world-system: African households as dialectical units of capitalist exploitation and indigenous resistance, 1890-1930. In the Journal of Philosophical Economics. Voulume IV. Issue 1. Special issue 2010.

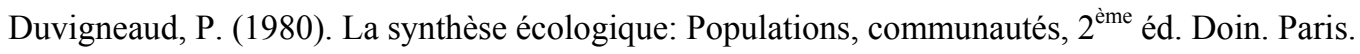

Egea, H. (2005). Voir et représenter la complexité: pour une methodos à base de pensée reliante. In Sixième Congrès Européen de Science des Systèmes.

Eurobarometer. (2010). Attitudes of Europeans towards the issue of biodiversity. Analytical report. Wave 2. European Commission.

FAO. (2007). Conflits Homme-Faune sauvage. In Nature \& Faune. Vol. 21, Edition 2.

Focus Biodiversité (2010). Documents de référence. Retrieved from http://www.projetdeterritoire.com/index.php/Les-ressources/Biodiversite/Documents-de-reference-guides-o utils-de-sensibilisation

Gulea, M. (2001). La communication non-verbale. In Les fondements de la communication face-à-face. Retrieved from http://www.biblioteca-digitala.ase.ro/biblioteca/carte2.asp?id=138\&idb

Hammill et al. (2009). Conflict-Sensitive Conservation. Practitioners' Manual. International Institute for Sustainable Development (IISD).

Hutton, J. (2010). Halting the loss of biodiversity-What next? Green Week, Brussels. UNEP-World Conservation Monitoring Centre.

ICA. (2008). Point sur la production de l'énergie électrique en Afrique. Framework outline for the annual meeting of the Infrastructure Consortium for Africa, March 13 and 14, 2008.

IEPF. (2006). Les agences d'électrification rurale en Afrique subsaharienne. Les politiques de maîtrise de l'énergie. Fiche technique Prisme n 7.

IUCN-CMP. (2010). Threats Taxonomy. Conservation Measures Partnership. Retrieved from http://www.conservationmeasures.org/initiatives/threats-actions-taxonomies/threats-taxonomy

Jolivet, R. (1962). Traité de philosophie. Introduction générale. Logique-Cosmologie. $6^{\text {ème }}$ édition. Emmanuel Vitte, éditeur. Paris. 
Karsenty, A., \& Pierre, J-M. (2005). Les concessions forestières en Afrique centrale. Aspects historiques, institutionnels et politiques, du point de vue de la responsabilité sociale et environnementale des entreprises concessionnaires. Rapport pour le projet GEPAC de l'Union Européenne. CIRAD, Montpellier.

Kasisi, R. (1989). La planification et l'application d'un développement durable comme principale stratégie de conservation des ressources dans la région du Parc National de Kahuzi-Biega (Zaïre). Université de Montréal. Thèse de doctorat (Ph.D.).

Kasisi, R., \& Jacobs, P. (2001). Strategies and action plans to conserve biological diversity: a cultural and scientific challenge. In Traditional Marine Resource Management and Knowledge, Bul. 13

Kasisi, R. (2010). La Convention Internationale sur la Diversité Biologique. Enjeux de mise en œuvre. Planification des aires protégées. pp. 89-107. Collection: Monde européen et international. CERIC (Centre d'Études et de Recherches Internationales et Communautaires) associé au CNRS. 235 pages.

Kasisi, R. (2010 in press). Conservation de la biodiversité: la complexité de la participation des populations dans la gestion des aires protégées. In les textes des présentations effectuées lors de la conférence AIB de l'UNESCO Science et Politiques de la Biodiversité pour la $37^{\mathrm{e}}$ session de la Conférence générale de l'UNESCO 2012.

Le Moigne, J-L. (2008). Relever le même défi: penser et agir à la fois. Pensée complexe et action intelligente. In Editorial de l'InterLettre Chemin Faisant - MCX-APC n 44 sept. - oct. 2008.

Le Pestre, P. (2011). Vingt ans après: Rio et l'avant-goût de l'avenir. Les Presses de l'Université Laval.

Mainka, S. A., \& Trivedi, M. (2002). Links between Biodiversity Conservation, Livelihoods and Food Security: the Sustainable Use of Wild Species for Meat. IUCN, Gland, Switzerland.

Mauz, I., \& Granjou, C. (2010). La construction de la biodiversité comme problème politique et scientifique, premiers résultats d'une enquête en cours. Sciences Eaux \& Territoires. Revue du CENAGREF. Numéro 03, Politiques publiques et biodiversité.

Morin, E. (1990). Introduction à la pensée complexe, ESF, Paris.

Morin, E., Motta, R., \& Ciurana, E-R. (2003). Éduquer pour l'ère planétaire. La pensée complexe comme méthode d'apprentissage dans l'erreur et l'incertitude humaines. Éditions Balland. Paris.

Morin, E. (2004). La méthode 6: éthique. Paris, Seuil.

Musibono, D. E. (2010). Les différents traités environnementaux sont-ils appropriés pour les populations des pays en développement (Afrique)? Retrieved from http://www.vertigo.revues.org/9398\#tocfrom1n2

Nègre, C. et al. (2010). La convention Internationale sur la Biodiversité: enjeux de mise en œuvre. Éditeur: la documentation française. 240 pages.

ONU. (2010). Perspectives mondiales de la diversité biologique 3. Troisième édition.

Paluku-Mastaki, C. (2005). Effectivité de la protection de la biodiversité forestière en République démocratique du Congo: cas du Parc national des Virunga (PNVI). La série des Etudes juridiques de la FAO en ligne (FAO Legal Papers Online). Retrieved from http://www.fao.org/fileadmin/user_upload/legal/docs/lpo43.pdf

PNUE. (2010). État de la biodiversité en Afrique. Fact Sheet.

Ramade, F. (1987). Les catastrophes écologiques, McGrawHill.

République française. (2010). La stratégie nationale pour la biodiversité: Bilan et perspectives. Conseil général de l'environnement et du développement durable.

Rodgers, W. A., Nabanyumya, R., Mupada, E., \& Persha, L. (2002). La conservation communautaire de la biodiversité des forêts denses en Afrique de l'Est est-elle viable? UNASYLVA, 53, 2002/2.

Russell, B. (1990). La philosophie de l'atomisme logique, French translation, in Ecrits de logique philosophique, PUF.

Sajaloli, B. (2007). Nature et religion: une sacrée géographie! Cafés Géographiques numéro (1175): p. 6.

Saussus, R. (1952). Livingstone et Stanley: Vers le Congo. Collection Lavigerie, n 40. Grands Lacs. Namur, 250.

TRAFFIC. (2010). Développement d'un système de suivi de la filière viande de brousse en Afrique Centrale: SYVBAC.

UICN, PNUE, \& WRI. (1995). Planification Nationale de la Biodiversité: principes directeurs basés sur l'expérience initiale des pays dans le monde. 
UICN-France. (2010). Stratégie nationale pour la biodiversité: Bilan général 2004-2010 et recommandations pour une nouvelle stratégie.

UNESCO, \& UNEP. (2003). Cultural diversity and biodiversity for sustainable development. Roundtable held on 3 September 2002 in Johannesburg during the World Summit on Sustainable Development. Pp. 59.

Vitrac, R. (2005). La théorie systémique des champs de pensées. TSCP. Décembre 2005.

Wilkie, D., \& Carpenter, J. (1999). The potential role of safari hunting as a source of revenue for protected areas in the Congo Basin. Oryx, 33, 339-345. http://dx.doi.org/10.1017/S003060530003074X

Wilson, E. O. (1992). The Diversity of Life. Harvard University Press. Cambridge, Massachusetts.

\section{Notes}

Note 1. These last three have been explored in several publications, but it is important to note that the word "conservation" has no legal basis, having been defined in the Convention on Biological Diversity by a tautology. See Kasisi, R. \& Jacobs, P. (2001).

Note 2. Specifically Ivory Coast, Gabon, Guinea, Mali, Sao Tome and Principe, and Chad.

Note 3. The conflict tree has been used for several projects of International Institute for Sustainable Development (IISD) as a tool for Conflict-Sensitive Conservation (CSC) analysis; see IISD (2009) and Brown \& Kasisi (2007).

Note 4. We must however note the contribution of eminent French ecologist Robert Barbault and many others who have written about the development of interdisciplinary issues in relation to the concept of biodiversity and whose biology conservation works are increasingly used as reference works in French-language universities worldwide.

Note 5. In the mid-1960s, the teaching of ecology in Québec was inspired by the humanism espoused by biogeographer Pierre Dansereau.

Note 6. See Boesten (2007). Free Choice or Poverty Alleviation? Population Politics in Peru under Alberto Fujimori. In European Review of Latin American and Caribbean Studies 82, April 2007. 3-20.

Note 7. http://www.conservationmeasures.org/initiatives/threats-actions-taxonomies/threats-taxonomy.

Note 8. Professor Jon Hutton is the Director of UNEP-WCMC (World Conservation Monitoring Centre). 